\title{
Fatigue behaviour of metallic components obtained by topology optimization for additive manufacturing
}

F.K. Fiorentin, B. Oliveira, J.C.R. Pereira, J.A.F.O. Correia, A.M.P. de Jesus

INEGI/Faculty of Engineering, University of Porto, Portugal

ffiorentin@inegi.up.pt, bttps://orcid.org/0000-0002-7352-8637

jcpereira@inegi.up.pt, bttps://orcid.org/0000-0002-0412-8728

jacorreia@fe.up.pt, bttp://orcid.org/0000-0002-4148-9426

ajesus@fe.up.pt, bttps://orcid.org/0000-0002-1059-715X

\section{F. Berto}

NTNU - Norwegian University of Science and Technology, Norway

filippo.berto@ntnu.no,https://orcid.org/0000-0002-4207-0109

\begin{abstract}
The main goal of the present research is to propose an integrated methodology to address the fatigue performance of topology-optimized components, produced by additive manufacturing. The main steps of the component design will be presented, specially the methods and parameters applied to the topology optimization and the post-smoothing process. The SIMP method was applied in order to obtain a lighter component and a suitable stiffness for the desired application. In addition, since residual stresses are intrinsic to every metallic additive manufacturing process, the influence of those stresses will be also analysed. The Laser Powder Bed Fusion was numerically simulated aiming at evaluating the residual stresses the workpiece during the manufacturing process and to investigate how they could influence the fatigue behaviour of the optimized component. The effect of the built orientation of the workpiece on the residual stresses at some selected potential critical points are evaluated. The final design solution presented a stiffness/volume ratio nearly 6 times higher when compared to the initial geometry. By choosing the built orientation, it is possible impact favourably in the fatigue life of the component.
\end{abstract}

KEYWORDS. Metallic Additive Manufacturing; Topology Optimization; Building Strategy; Residual Stress; Fatigue Life Prediction; Multiaxial Criterion.

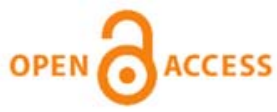

Citation: Fiorentin, F.K., Oliveira, B., Pereira, J.C.R., Correia, J.A.F.O., Jesus, A.M.P., Berto, F., Fatigue Behavior of Metallic Components Obtained by Topology Optimization for Additive Manufacturing, Frattura ed Integrità Strutturale, 55 (2021) 119-135.

Received: 25.08 .2020

Accepted: 20.10 .2020

Published: 01.01.2021

Copyright: (C) 2021 This is an open access article under the terms of the CC-BY 4.0, which permits unrestricted use, distribution, and reproduction in any medium, provided the original author and source are credited. 


\title{
INTRODUCTION
}

\begin{abstract}
A dditive Manufacturing (AM) processes are creating new design opportunities for structural components, allowing structural optimization to be explored without traditional manufacturing restrictions. AM processes allow a massive autonomy of design, which may result in significant reductions of weight, while maintaining the main function of the component. However, this geometrical design may have repercussions in the fatigue strength due to stress concentrations and residual stresses promoted by the thermal effects during the AM process.

Many efforts are being dedicated to reach mechanical properties on additive manufactured components close to the conventional counterparts. Right now, the AM has much to evolve in order to meet the industry requirements. Therefore, problems associated with costs, production speed, mechanical performance, surface quality and homogeneous microstructures have to be addressed [1]. Structural optimization improves additive manufacturing benefits, since there is a perfect symbiosis between these two methods. Both of these methods aim at providing freedom to the designers or engineers. The topology optimization algorithms are adapted to simulate structures with complex shapes, optimizing them to meet the desired mechanical performance. Lightweight designs are a reality when these technologies are combined, reducing the amount of manufacturing operations required, but increasing the importance of the product development. Fig. 1 illustrates this new product development outlook [2].
\end{abstract}

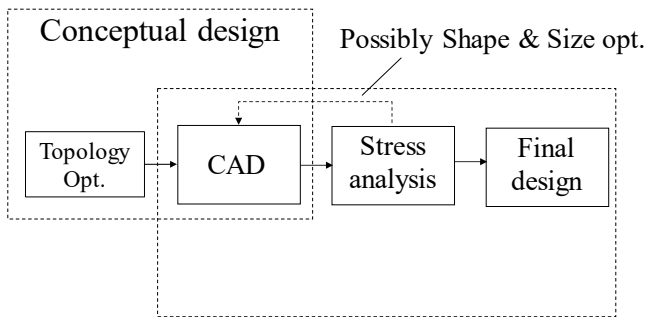

Figure 1: Product development process [2].

Additive manufacturing does not cover a single, but a range of different technologies. These technologies can explore not only the freedom of new designs but can also process parts using several different materials. Currently, AM has been mostly used with polymers and metals, despite composites and ceramics are increasing their relevance too. The current processes for metals encompass methods such as Binder Jet, Powder Bed Fusion (PBF), Sheet Lamination (SL) and Directed Energy Deposition (DED) processes. Powder Bed Fusion is one of the most popular MAM processes. It uses a heat source to selectively melt thin layers of metal powder, welding one layer to the previous, forming a solid component. The heat source, laser or electron beams, differentiates this category into Selective Laser Melting (SLM) or Selective Laser Sintering (SLS) or Laser Powder Bed Fusion (LPBF) and Electron Beam Melting (EBM) [3].

Selective Laser Melting offers the opportunity to generate components with complex shapes and provides one of the best surface qualities among the AM processes. During this process, a layer of powder is deposited onto a substrate and is spread by a re-coater. After that, a laser beam melts this powder according to specific process parameters (laser power, beam diameter, modulation and scan strategy). Afterwards, the melted material solidifies and retracts. Subsequently, a new powder layer is deposited. This process is repeated layer upon layer until the part is completed. The remaining (un-melted) powder is removed from the building chamber and most of the times it will be recycled [4][5][6]. Due to the described intrinsic characteristics of the process, residual stresses are typically developed within the part, which contributes to the part distortion and would disturb the stress fields due to the external loads applied into the part.

Investigations related to the mechanical properties of the AM parts [7] show that, comparing the microstructure of parts produced by SLM with the wrought material, the elongation for wrought is usually a little bit higher. Parts produced by SLM are near full density and have good mechanical properties, the thermal stresses that these parts are subjected to may cause distortions and micro-cracks. During SLM, the trapped gases, un-melted powder and oxidized particles lead to porosity in the component. These defects inside the material and in the surface may favour crack propagation and lead to premature failure of the component under dynamic/fatigue loads. SLM process allows a wide range of materials processing, such as titanium alloys (e.g.Ti-6Al-4V), stainless steel, nickel-based alloys (Inconel) and aluminium alloys [8][9]. The fatigue characterization of AM materials has been received intensive research focus in the recent years [10-13].

Nevertheless, the research about the fatigue behaviour of real components has deserved little attention, most likely due to yet limited knowledge about AM material fatigue behaviour and the complex interaction between the manufacturing 
parameters and the structural performance of the components (e.g. residual stresses, defects, anisotropy, distortions, surface finish).

In the current investigation, an integrated methodology (full process digital twin) from design to structural fatigue performance assessment is proposed and illustrated for a typical bracket part often presented in the literature as a case study for topological optimization and additive manufacturing [14][15]. The proposed design methodology will involve a first stage of topological optimization, followed by process additive manufacturing simulation and finally fatigue assessment based on process simulated residual stresses combined with stress field from external load application.

\section{METHODS}

7 he current section presents the problem definition and the objectives are presented which will support the presentation of the proposed methodology. In addition, the necessary analytical and numerical formulations are described, encompassing the methodologies applied for topology optimization, the residual stresses computation resulting from additive manufacturing and the formulation for the fatigue damage assessment.

\section{Problem definition}

The proposed methodology will be demonstrated using a case study from aerospace industry, consisting of a holding support element, commonly called "bracket". In particular, a bracket developed through topological optimization and produced thru AM for the Airbus A350 XWB [14][15], as shown in Fig. 2, was considered in this study. This element makes part of the suspension of the flight crew rest compartments, which is attached to the primary structure of the aircraft [14][15]. This component was selected as a reference in this work for topological optimization, additive manufacturing simulation and fatigue analysis. The selection of an existing part was important, once it allows the comparison between the proposed optimization solution and the existing one for the bracket. The part dimensions, as well as the forces and boundary conditions applied, were obtained from Kranz [14] and are summarized in Tab. 1. Despite the original bracket was built It was decided to establish the 316L stainless steel as the working material. This material presents good mechanical properties and is popular in AM applications, mainly because of its excellent corrosion resistance resulting from the nickel and molybdenum contents in the alloy and excellent stability during processing [12]. The elastic and plastic hardening behaviours of the material were based on literature data, the respective parameters being presented in the Tab. 2. This data was used in numerical analysis (on both the AM simulations and structural analysis under cyclic load), allowing to reproduce the elastoplastic behaviour of the material, combining the isotropic and cyclic hardening of the material. However, for the optimization analysis, only the elastic analysis was used.

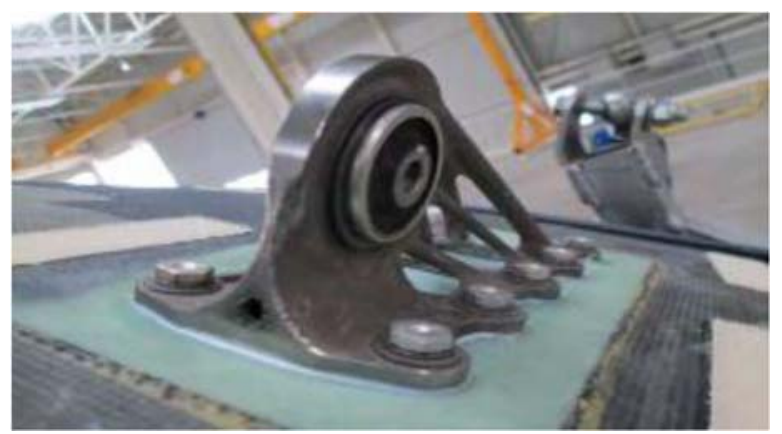

Figure 2: Airbus ALM/3D printing FCRC cabin bracket installation [14][15].

Besides the original part has been built in aluminium alloy, it was decided to establish the 316L stainless steel as the working material. This material presents good mechanical properties and is popular in AM applications, mainly because of its excellent corrosion resistance resulting from the nickel and molybdenum contents in the alloy and excellent stability during processing [16]. The elastic and plastic hardening behaviours of the material were based on literature data, the respective parameters being presented in the Tab. 2. This data was used in numerical analysis (on both the AM simulations and structural analysis under cyclic load), allowing to reproduce the elastoplastic behaviour of the material, combining the isotropic and cyclic hardening of the material. However, for the optimization analysis, only the elastic analysis was used as previously referred. 
As regards the fatigue study, the relation of the applied stress range and the number of cycles to failure is described by means of the SN curve estimated for a stress ratio of $\mathrm{R}=-1$, shown in Fig. 3 [17]. This curve will be used later to estimate the fatigue life of the optimized part taking into account the effect of residual stresses promoted by additive manufacturing process and service load.

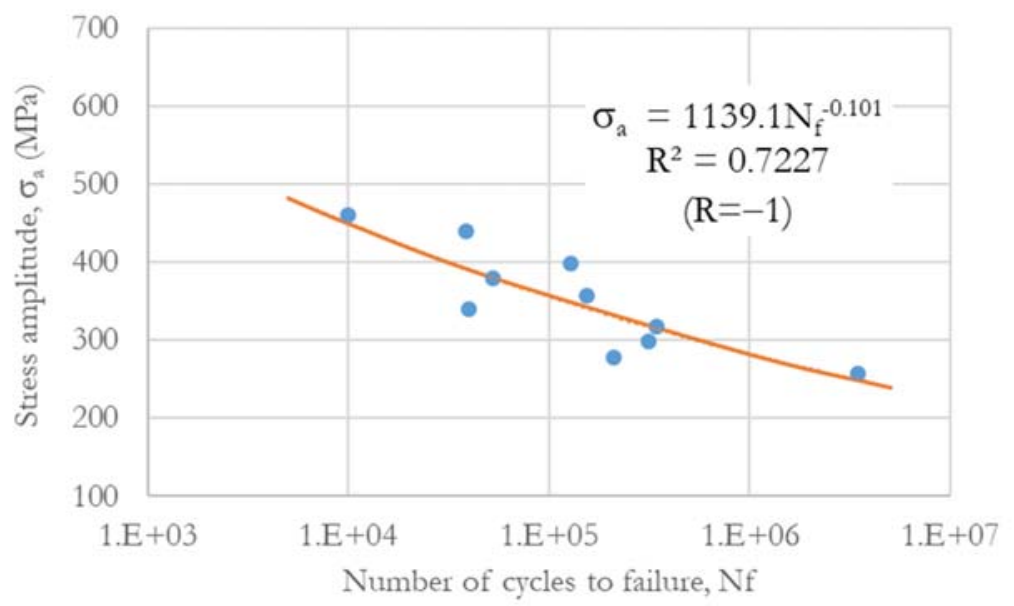

Figure 3: S-N curve of the 316L (11 Hz) [17].

\begin{tabular}{ccccc}
\hline Designation & Function & Material & $\begin{array}{c}\text { Dimensions } \\
(\mathrm{mm})\end{array}$ & $\begin{array}{c}\text { Weight } \\
(\mathrm{g})\end{array}$ \\
\multirow{2}{*}{ FCRC-bracket } & Load transfer & $\mathrm{Al} \mathrm{7075}$ & $\begin{array}{c}160.5 \times 65 \times 65.5 \\
(\mathrm{y}, \mathrm{z}, \mathrm{x})\end{array}$ & 226 \\
\hline
\end{tabular}

Table 1: Technical data of the original bracket component [14].

\begin{tabular}{|c|c|c|c|c|c|c|}
\hline \multirow{2}{*}{$\begin{array}{l}\text { Young Modulus } \\
\qquad \mathrm{E}(\mathrm{GPa})\end{array}$} & \multirow{2}{*}{$\begin{array}{l}\text { Poisson } \\
\text { ratio }\end{array}$} & \multirow{2}{*}{$\begin{array}{c}\text { Yield } \\
\text { Stress } \\
\sigma_{0}(\mathrm{MPa})\end{array}$} & \multicolumn{2}{|c|}{ Kinematic Hardening Parameters } & \multicolumn{2}{|c|}{ Isotropic Hardening Parameters } \\
\hline & & & $\mathrm{C}(\mathrm{MPa})$ & $\gamma$ & $\mathrm{Q}(\mathrm{MPa})$ & $\mathrm{b}$ \\
\hline 200 & 0.3 & 211 & 57.81 & 619.04 & 42.3 & 21.6 \\
\hline
\end{tabular}

Table 2: Properties of the 316L stainless steel adopted in this study [18].

The boundary conditions adopted for the bracket are illustrated in Fig. 4. The load direction is specified together with the displacement constraints at base plane. While the load is to be applied thru a spherical bearing, the displacement constraints are applied thru 10 bolts. The optimization domain for the bracket is illustrated in the Fig. 5. The boundary condition used was "encastre" of the bottom of the bushing connector to simulate the bolts tightening and a longitudinal symmetry plane was used in order to reduce the computational cost (once it reduces the number of required elements by half). This model encompasses the stiffness of the bolt in several directions. It was assigned local seeds to the regions of the fasteners and to the hole where the load was applied. The loading during working conditions was applied at the centre of the ring, as shown in Fig. 5b. A reference point was used, the load was applied to this point and distribute around the internal surface at the ring. All degrees of freedom between these nodes and the reference point were constrained, expect the rotation around the bearing axis, z-axis (since it was a bearing, the shaft was supposed to rotate freely around its axis). The initial mass of this part was $2.10 \mathrm{~kg}$. A mesh refinement study was performed for a static analysis and the final mesh approximate global element size chosen was $1.5 \mathrm{~mm}$.

\section{Topology Optimization}

The topology optimization methods are based on results of finite element analysis (FEA), which are applied in order to evaluate how a structure behave to different actions like forces, vibration, heat, fluid flow and so forth. FEA requires a mesh to divide the part into finite elements, which have material properties assigned to them. The importance of the mesh is 
undeniable on FEM and topology optimization. However, the mesh has a high impact on computation time. This impact gains even more relevance because topology optimization is computationally expensive by itself. For three-dimensional topology optimization, the most common elements are the tetrahedral and hexahedral. Since the tetrahedral allows an easily mesh generation in less computation time, it is usually more convenient. However, in some situations, the hexahedral elements are more suitable [19].

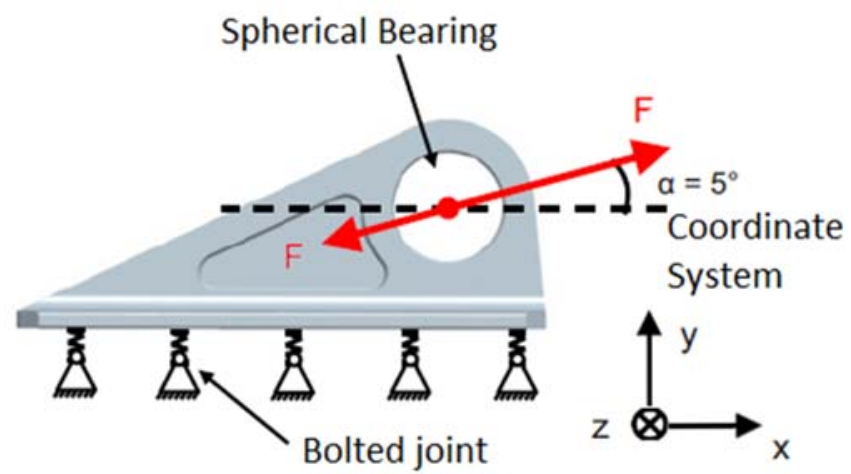

Figure 4: Boundary conditions and coordinate system applied to the bracket [14].

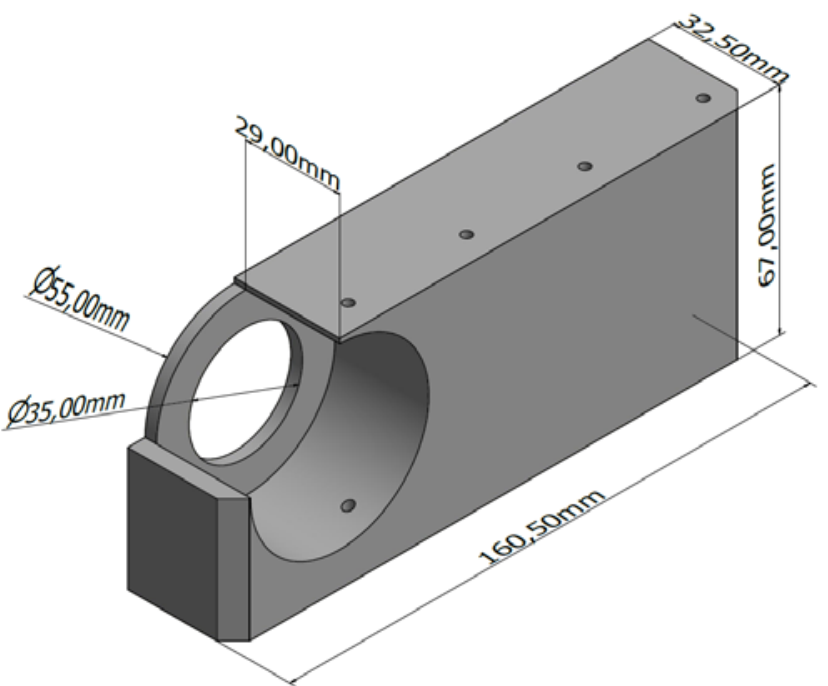

a)

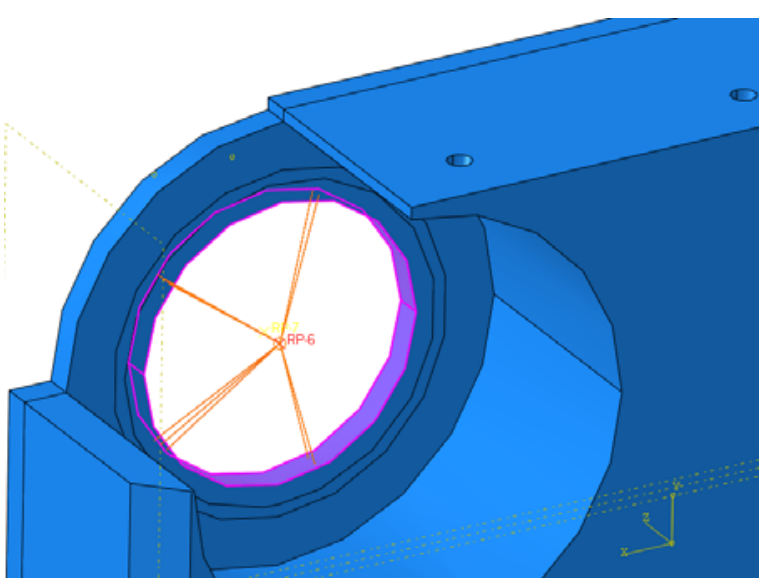

b)

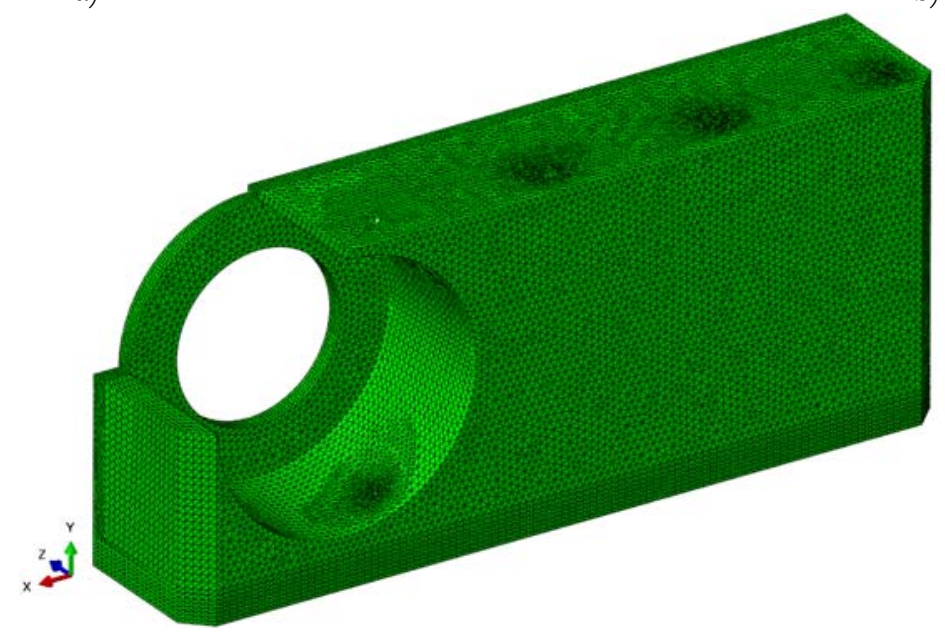

c)

Figure 5: 3D part for topology optimization: a) geometry and dimensions in mm of starting geometry; b) coupling constraint to simulate the spherical bearing; c) finite element mesh of solid block. 
According to the well-established theory of Bendsoe and Sigmund [20], most of the optimization methods are applied to find and solve a minimum strain energy design (also called compliance method) with a volume constraint, and this was applied to the present study. The objective function to be minimized is:

$$
\min c=U^{T} K U=\sum_{e=1}^{n} u^{e} k^{e} u^{e}=\sum_{e=1}^{n}\left(\varrho^{e}\right)^{p} u^{e} k_{0} u^{e}
$$

where the c represents the strain energy, $\boldsymbol{K}$ means the global stiffness matrix, $\boldsymbol{U}$ is displacement vector, $\varrho^{\mathrm{e}}$ is the relative element density (being 1 the solid element and 0 a "void"), $\boldsymbol{u}^{\boldsymbol{e}}$ is the element displacement vector, $\boldsymbol{k}^{\boldsymbol{e}}$ is the element stiffness matrix after density interpolation and $\boldsymbol{k}^{0}$ is the initial stiffness matrix [21].

The constraint was the maximum volume, which for this case could not exceed the $12 \%$ of the initial optimization domain. It is important to emphasize that not the entire workpiece was inside the optimization domain, the regions around the load application and the fasteners were selected to be outer of optimization domain (therefore they were not changed during the optimization loop). The constraint can be written as:

$$
V^{*}-\sum_{e=1}^{n} \mathrm{~V}^{e} e^{e}>0
$$

where $V^{*}$ represents the constraint volume, $n$ is the total number of elements and $V^{e}$ is the volume of the element. It can be also stipulated a minimum density, $\varrho_{\min }$, for the element, this is a good practice once it does not allow elements with very low stiffness to be created. On the other hand, if a very high @min is used, usually the code is "discouraged" to create new elements paths and the optimization might not converge well to a satisfactory minimum. The minimum density law can be written as:

$$
0<\varrho_{\min } \leq \varrho^{e} \leq 1
$$

Solid isotropic material with penalization (SIMP) is the approach that offer inherent simplicity and favourable complexity and it is abundantly used in modern topology optimization problems. SIMP is a soft-kill method and it is used to discretize the design domain dividing it into a grid of $N$ elements (isotropic solid microstructures) each element having a fractional material density [22]. With the density function varying between 1 and 0 , it will create a variable density gradient in the new domain. The solid isotropic microstructure with penalization approach represents the intermediate density material with a tensor:

$$
K_{i j k l}(\varrho)=K_{i j k l}^{0} \times \rho^{p}
$$

where the original stiffness tensor of solid material $K_{i j k l}^{0}$ is penalized by a density factor. The penalization factor $p$ forces the algorithm to converge to a solution that contains only a solid or a void by lowering the participation of fractional density elements, encouraging the development of elements with densities close to 1 or 0 . Usually the proportional stiffness model is used, where the penalized density will be essential to define the new penalized stiffness, which can be written as:

$$
K_{i j k l}(x)=\rho(x)^{p} K_{i j k l l}^{0}, p>1
$$

The penalty function heavily influences on density and consequently on the penalized stiffness. For $p>1$ the stiffness will be very low for low density values and it is not recommended.

The topology optimization procedure has been carried out in ABAQUS with the SIMP algorithm. The workflow of the optimization loop is shown in Fig. 6. The initial stage of the simulation is a structure with $100 \%$ density elements. At each loop, a structural simulation is performed. For each step (with a known density of elements) a sensitivity analysis is developed, where the influence of the elements density on the objective function is evaluated. After the optimization procedure is concluded, it is possible to extract the optimized geometry; a threshold called ISO value is usually set to regulate which elements are displayed. The ISO value must be between zero and one. If the ISO value is very high, the part surface 
will shift toward the inside of the model decreasing its volume. For example, for an ISO value of 0.5 , the results only show the elements with densities above $50 \%$. The most recommended values for this parameter is ISO $=0.3-0.5[23,24]$.

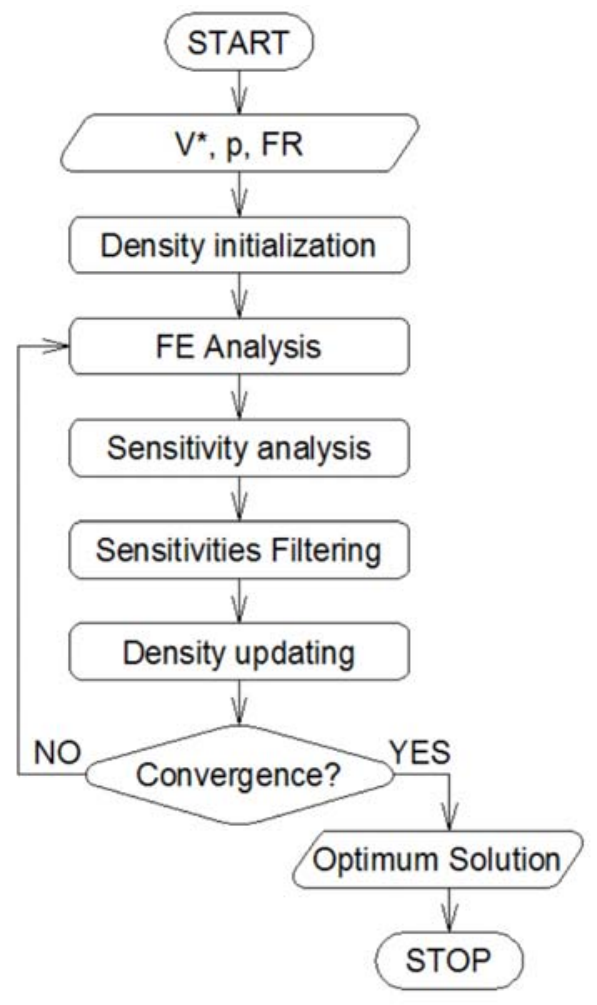

Figure 6: Flow chart of SIMP algorithm [22].

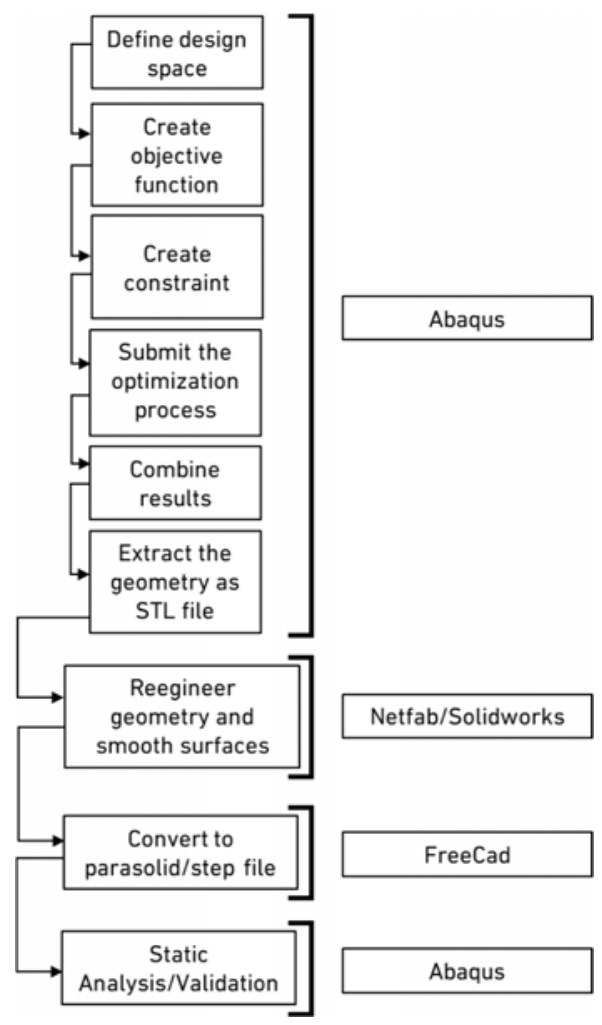

Figure 7: Topology optimization workflow.

After extracting the corresponding STL file resulted from the optimization process, which only describes the surface geometry of a three-dimensional object, it is critical to remove/smooth potential areas that can promote stress concentration. Reengineer the part is also important, once it is necessary to interpret the shape of the geometry obtained taking into account the functional conditions of the part. It should be noted that the optimization process leads to an initial approach of the final part. In fact, if there is a significant hole that is an interface of the component or if it is found a lack of material in certain areas, it is essential to correct it in order to avoid weak regions and/or without potential stress concentration. The post-processing of the optimized component was done manually, the flow chart containing the steps of the process and the software used can be seen in Fig. 7.

\section{Residual stresses in Additive Manufacturing}

For simulating the additive manufacturing process of this part from a case study, a commercial software was used, the ESI Additive Manufacturing. Simulating the manufacturing procedure is a complex task, especially for the Powder Bed Fusion Process, which encompasses different fields of study. Looking at the metallurgical component of the process, it involves melting and solidification of the material, in some cases multiphase materials, several grain sizes depending on the cooling rate, porosity and other defects and so on. The heat transfer of the process is also complex, a moving heat source is present, properties like conductivity, absorptivity, emissivity and specific heat are temperature dependent, the powder and the bulk material present very different properties. In addition, the process involves huge cooling rates and temperatures gradients, where conductivity, convection and radiation take an important role. Therefore, to make it possible to simulate the manufacturing process, some assumptions and hypothesis are required.

For the present numerical analysis, the material properties used were constant (average values from properties at melting and room temperature were used). Also, the "full-layer" strategy was used. This strategy ignores the laser path and assumes that an entire layer is solidified at once. This simplification makes it possible to simulate the process without having to perform a heat transfer analysis, coupled with a structural simulation. For every new layer, a mechanical analysis is performed. The initial temperature for this new layer is the melting temperature and the final temperature for it is the 
chamber temperature. The other layers and baseplate are always at the chamber temperature. In other words, for every new layer, a structural problem where a layer cool-down form solidus temperature to chamber temperature is solved, which can be summed as a thermal contraction problem. For a unidirectional problem, the governing equation is:

$$
\Delta L=\alpha L_{0} \Delta T
$$

where $\Delta L$ is the difference between final length, $a$ is the linear expansion coefficient, $L_{0}$ is the initial length and $\Delta T$ is the difference between final and initial temperatures. As the new layer wants to contract, the previous layers and baseplate will provide resistance, generating residual stresses. Using a mechanical analysis, the applied load will be equivalent to the thermal strain supplied by the process (due to the thermal contraction/expansion). Previous works were able to successfully estimate the workpiece distortion (and, consequently, the residual stresses) using similar approaches, validating the numerical results by experimental measurements [25].

Fig. 8 shows the three stages of the process simulation. The first stage is the building of the workpiece, it starts only with the baseplate and ends up with the part completely built. During the building process, the baseplate is clamped to the machine structure. The second stage is the release of the baseplate from the machine. Finally, the last stage is the removal of the workpiece, where the supports and baseplate were detached. The residual stresses presented during the working conditions are the same as the ones from the last building stage, therefore this will be used to perform the fatigue assessment. It can be noticed that a workpiece with the same final form can present different residual stress fields if some parameters are changed, like its building orientation. At this study, three building orientations were simulated and their respective effect on the residual stress field. Therefore, the full part simulation was used instead of taking advantage of the longitudinal symmetry plane used in the topology optimization simulation. The AM simulations considered elastic-plastic properties of the material (see Tab. 2). In addition, the solidification temperature of $1673.15 \mathrm{~K}$ was assumed with an expansion coefficient of $1.99 \times 10^{-5}$.

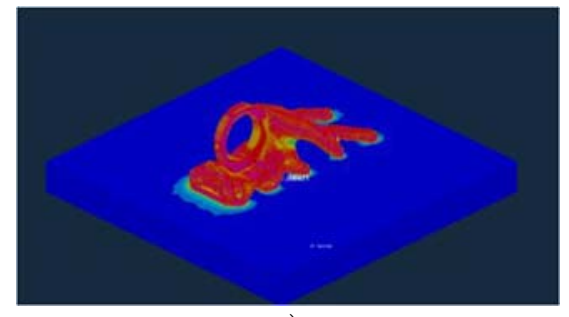

a)

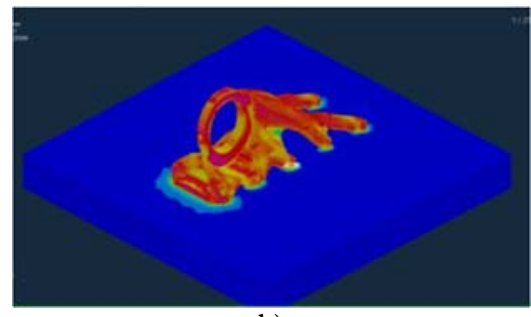

b)

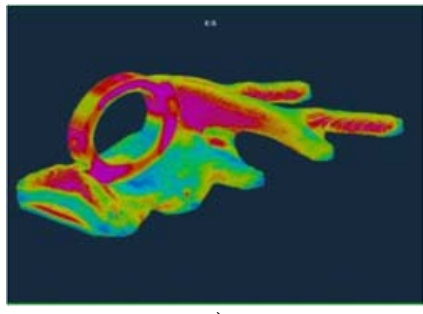

c)

Figure 8: Stages of the simulation: (a) building process, (b) releasing build plate from the machine, (c) removal of the workpiece from the base plate.

\section{Fatigue Assessment}

Concerning the fatigue assessment, firstly a cyclic stress analysis of the optimized component, without residual stresses, and a load ratio, $R=-1$ was conducted in $A B A Q U S \AA$, allowing estimating the evolution of the stresses and the identification of potential critical locations. From the cyclic elastoplastic analysis, the alternating and mean stresses required for fatigue analysis are computed. Due to the applied load ratio, the referred analysis would lead to null mean stresses (minimum and maximum stress values are symmetrical). However, this result could lead to the wrong assumption that the workpiece is absent from mean stresses. As the workpiece was designed to be additive manufactured, it will present significant residual stresses, which will effectively act as the mean stress during external loads. This leads to another conclusion - different locations of the workpiece will present different residual stress, resulting on different mean stresses, which would impact in fatigue damage. In addition, construction parameters, including build direction, will influence the residual stresses and the fatigue behaviour. A fatigue model sensitive to the mean stress is therefore needed for the present study. In addition, the load applied to the optimized bracket would lead to multiaxial stress fields that need to be addressed by a convenient multiaxial proportional fatigue damage model.

A cyclic quasi-static analysis was performed on the workpiece, applying the working load as the external force. After this analysis, the most critical regions were selected to be further studied. From these nodes, the alternating stresses were extracted. However, the geometry covered in this work is complex, and it presents multiaxial stresses fields. So, this stress state must be represented into a scalar. The octahedral shear stress theory (Von Mises) was used to find this scalar, and is calculated as: 


$$
S_{q a}=\frac{1}{\sqrt{ } 2} \sqrt{\left(S_{a 1}-S_{a 2}\right)^{2}+\left(S_{a 2}-S_{a 3}\right)^{2}+\left(S_{a 3}-S_{a 1}\right)^{2}}
$$

where $S_{a 1}, S_{a 2}$ and $S_{a 3}$ are the principal stress amplitudes.

For several applications, the octahedral shear stress theory can be applied with success, but in the case of mean stress effect on fatigue, it is not suitable. The main reason is that it removes the information about the stress being compressive or tractive. For the fatigue analysis, this information makes all the difference, a workpiece under compression will not fail due to cyclic loads, and a workpiece under tensile loads will have a premature failure. To solve these issue, one may consider the sum of the principal mean normal stresses [26]:

$$
S_{q m}=\left(S_{m 1}+S_{m 2}+S_{m 3}\right)
$$

where $S_{q m}$ is the equivalent mean stress, $S_{m 1}, S_{m 2}$ and $S_{m 3}$ are respectively the first, second and third principal mean stresses. According to the formulation of Eqn. (8), the mean stress can be either positive and negative, which better represents the beneficial effect of compressive mean stress and the adverse effect of tensile mean stress on fatigue behaviour. Coupling the information about the alternating stress (due to the loading conditions) and the mean stress (resultant from the building process), it is necessary to combine these two formulations. One of the most used approaches in this case is the Sines method [27], which is represented as:

$$
\sqrt{\left(S_{a 1}-S_{a 1}\right)^{2}+\left(S_{a 2}-S_{a 3}\right)^{2}+\left(S_{a 3}-S_{a 1}\right)^{2}}+m\left(S_{m 1}+S_{m 2}+S_{m 3}\right)=\sqrt{2} S_{N f}
$$

where $m$ is the coefficient of mean stress, normally 0.5 [26].

Since the formulations for both alternating and mean stress were proposed, it is necessary to identify the regions of interest. The critical regions for the alternating stress may not (and most likely will not) be the same as the ones for residual stresses (mean stress). Also, depending on the building orientation chosen for AM process, the residual stress will change, and the critical regions as well. In order to encompass both the most critical points for residual stress and alternating stress, 6 points have been choosing, being 3 of them selected based on the alternating stress field and 3 of them based on the residual stress. For the cyclic analysis, the 3 points chosen will be designated simply as "Point 1", "Point 2" and "Point 3". Since these points are only based on the working load (alternating stress), changing the building orientations will have no effect on their alternating stress, therefore these points will be studied in all building orientations. Regarding the critical regions associated to the highest residual stresses, 3 building orientations were studied. For each orientation, the 3 most critical points for residual stress were chosen (and their location may be different for each building orientation studied). They will be called "Point 4", "Point 5" and "Point 6" for building orientation 1; "Point 7", "Point 8" and "Point 9" for orientation 2 and "Point 10", "Point 11" and "Point 12" for orientation 3. Summing up, 6 points for each orientation will be studied, add up to 12 points, being 3 of them common to all building orientations. At the following section, the locations for these points and their results will be discussed.

The final goal is performing the estimative about the number of cycles to failure in each point, according to each orientation, and it can be obtained by the application of the SN curve of the material, shown in Fig. 3, as:

$$
S_{N f}=C N^{m}
$$

where $N$ is the number of cycles, and the values used for $C$ were $1139.1 \mathrm{MPa}$ and for $m$ was -0.101 [17].

\section{RESULTS AND DISCUSSION}

T hrough the numerical procedure described on subsection Topology Optimization, an optimized geometry was reached. The obtained design is shown in Fig. 9. It is important to emphasize that the presented geometry only shows elements of densities higher than $50 \%$ (ISO-value $=0.5$ ), and it was used merely as a plot tool. As it can be seen in Fig. 9 and Fig. 10, the obtained geometries presented some sharp edges and irregular surfaces, most of them related to the mesh refinement (since the topology optimization is very computationally expensive, a very fine mesh would be impractical) 
and the imposed boundary conditions. The structural FE analyses performed after the optimization using this geometry have shown that these locations presented peak stresses. Therefore, a post-processing based on smoothing and repairing operations on these surfaces was performed using the Netfabb software. The final workpiece is presented on Fig. 11 and it can be seen that the previous critical regions are much smoother, resulting on more homogeneous stress fields. The mass was reduced to $12.53 \%$ of the initial mass. This value is different from the constraint in topology optimization. This discrepancy can be explained because the workpiece was submitted to reverse engineering (post-processing) that added material to the part as well as regions around the interface of the part were excluded from the optimization domain. In order to investigate the stiffness of the bracket, a static analysis for both geometries (before and after the optimization) was performed. The displacement magnitude of the reference point (located at the centre of the hole) was extracted for both analysis and divided by the load magnitude. The stiffness achieved for both geometries had a difference of $23 \%$ and since for stiffness-to-weight ratio, only the mass changes significantly, this ratio is significantly higher for the final geometry, compared to the initial one. The mass properties, stiffness and stiffness-to-mass ratio are presented in Tab. 3 .

Using the final design, it has been possible to simulate the workpiece performance under cyclic loads. Fig. 12 shows the Von Mises stresses field of the component, for the current image the peak load of $34155 \mathrm{~N}$ was used. It can be seen that the higher stresses are below $400 \mathrm{MPa}$, being most of the regions under $150 \mathrm{MPa}$. It is important to emphasize that this analysis does not encompass the residual stresses, being presented only the influence of the working/external cyclic loads. Later, these results will be combined with the residual stress promoted by the AM process and estimates about the fatigue behaviour of the component will be performed.

\begin{tabular}{cccc}
\hline Design stage & $\begin{array}{c}\text { Mass } \\
(\mathrm{g})\end{array}$ & $\begin{array}{c}\text { Stiffness } \\
\left(\mathrm{Nmm}^{-1}\right)\end{array}$ & $\begin{array}{c}\text { Stiffness to weight ratio } \\
\left(\mathrm{Nmm}^{-1} \mathrm{~g}^{-1}\right)\end{array}$ \\
Initial & 2100 & $1.96 \times 10^{5}$ & 93 \\
Final & 263 & $1.52 \times 10^{5}$ & 578 \\
\hline
\end{tabular}

Table 3: Initial and final mass and stiffness of the bracket.

\begin{tabular}{|l|}
\hline MAT_PROP_NORMALIZED \\
(Avg: $75 \%)$ \\
$+1.000 \mathrm{e}+00$ \\
$+9.167 \mathrm{e}-01$ \\
$+8.335 \mathrm{e}-01$ \\
$+7.502 \mathrm{e}-01$ \\
$+6.670 \mathrm{e}-01$ \\
$+5.837 \mathrm{e}-01$ \\
$+5.005 \mathrm{e}-01$ \\
$+4.172 \mathrm{e}-01$ \\
$+3.340 \mathrm{e}-01$ \\
$+2.508 \mathrm{e}-01$ \\
$+1.675 \mathrm{e}-01$ \\
$+8.425 \mathrm{e}-02$ \\
$+1.000 \mathrm{e}-03$ \\
\hline
\end{tabular}
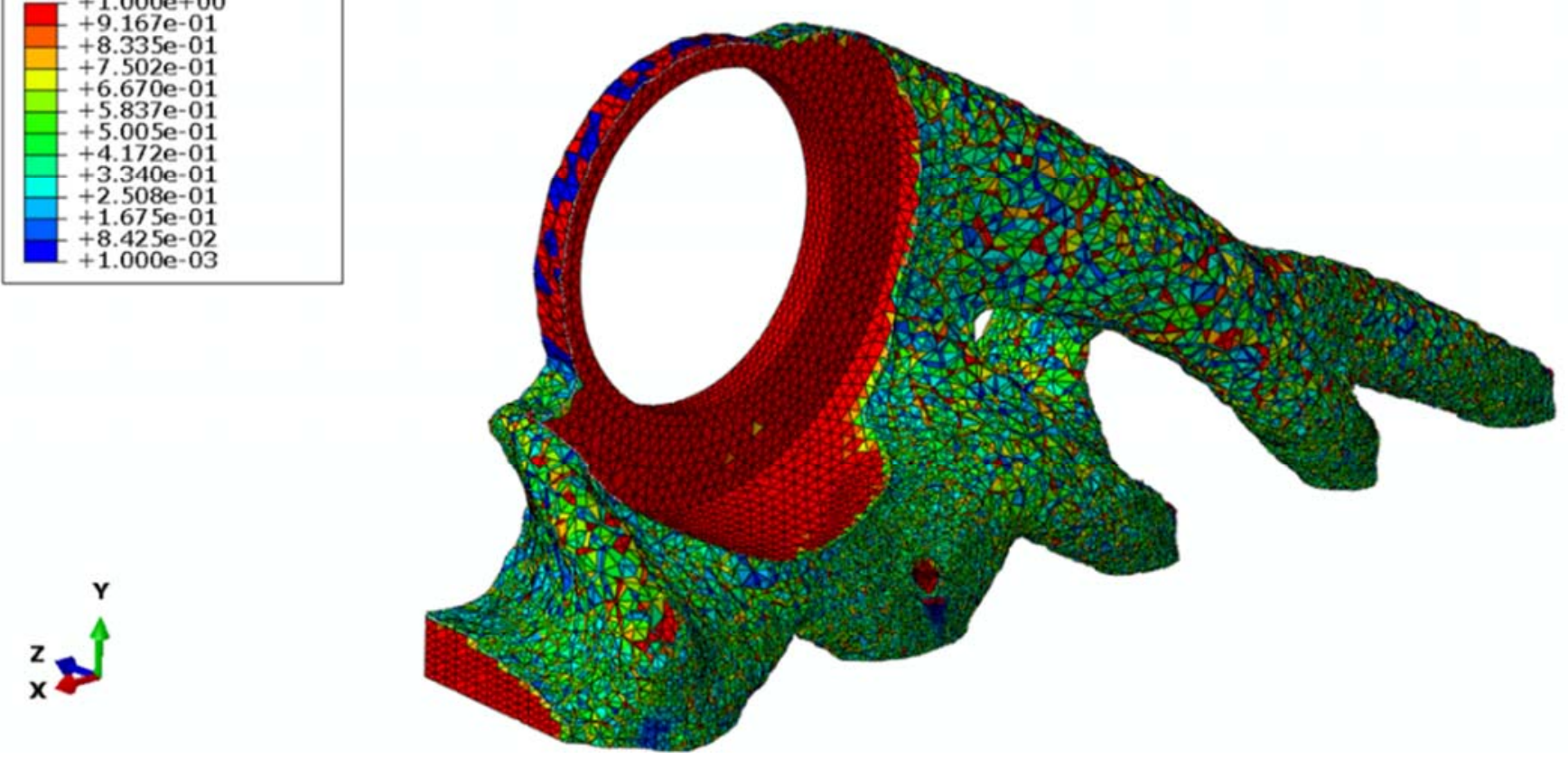

Figure 9: Extracted geometry from TO (ISO-value=0.5). 
With the final bracket geometry defined, it was also possible to simulate the AM process of it and compute the residual stress and distortions during and after the manufacturing process. Three building orientations were studied; this was performed in order to identify which building orientation was the most suitable for the final goal of the workpiece. In other words, the best orientation would be the one which presented lower residual stress on critical points, improving the number of cycles that the component can handle before failure. Preferably, compressive residual stresses at hot spots would be desirable.

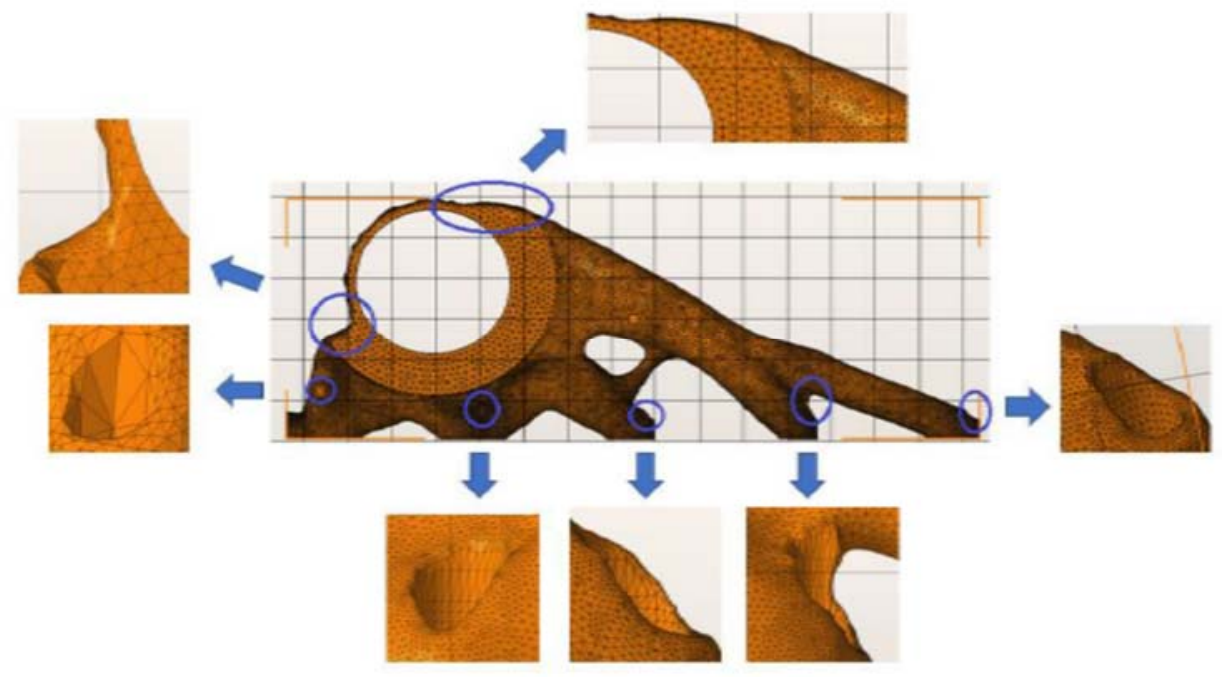

Figure 10: Topology optimization result before smoothing.
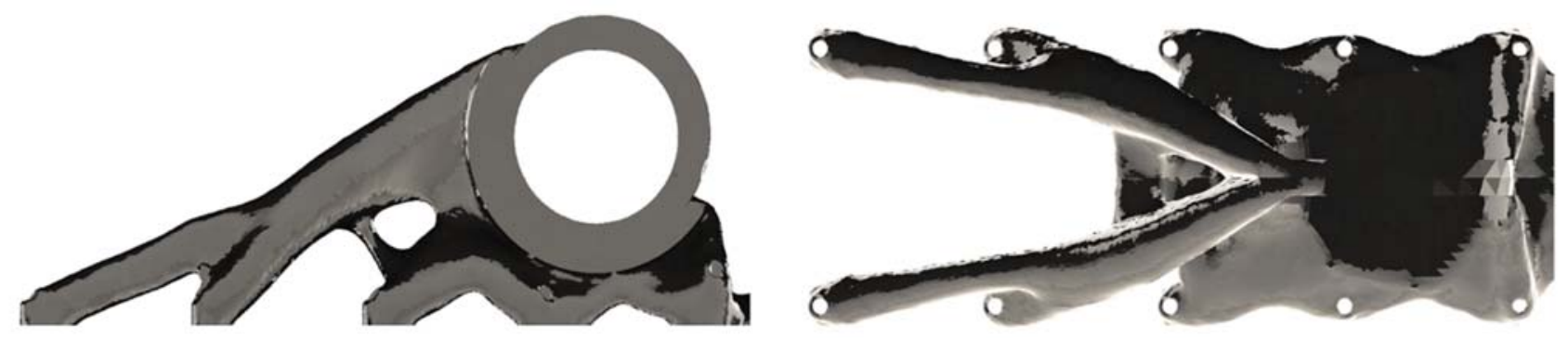

Figure 11: Final geometry of the case-study part after smoothing operation.

Fig. 13 presents the residual stress for Orientation 1. It can be observed that residual stress are not negligible, once they create regions of the workpiece under plastic deformation. The residual stress presented here are the ones existing after the baseplate removal; this was performed because this is the residual stress field the workpiece will be subjected to during the working conditions assuming there will be not extra post-processing applied to the part. Fig. 14 presents the residual stresses for Orientation 2. It is possible to see that the maximum values are similar to the previous orientation. However, it is important to notice that they happen in different locations, and this is relevant because if these regions are not critical during the working load, they will not reduce the fatigue life of the component (the actual stress during the operation is a superposition of the stresses originated by the loads and the residual stresses). The results for the third orientation are shown on Fig. 15. Once more, the maximum stresses are around the same value as the previous orientations.

Combining both the stress results from external cyclic loads applied thru the spherical bearing and the ones originated by the manufacturing process (residual stresses), it is possible to combine these results and perform a fatigue assessment. As referred earlier the 6 th most critical points were evaluated, being 3 of them originated from the working loads and the remaining points taking according to the residual stress. Fig. 16 illustrates the selected points. It is important to notice that all points were located at the surface. This happened for several reasons; first of all the surface is the region where the tensile residual stress are usually located; secondly, during the load conditions, the nodes at the surface were the ones with higher stresses; finally, for the fatigue assessment, the surface is very important, mainly because there is where the cracks initiation happens, most of the times. 

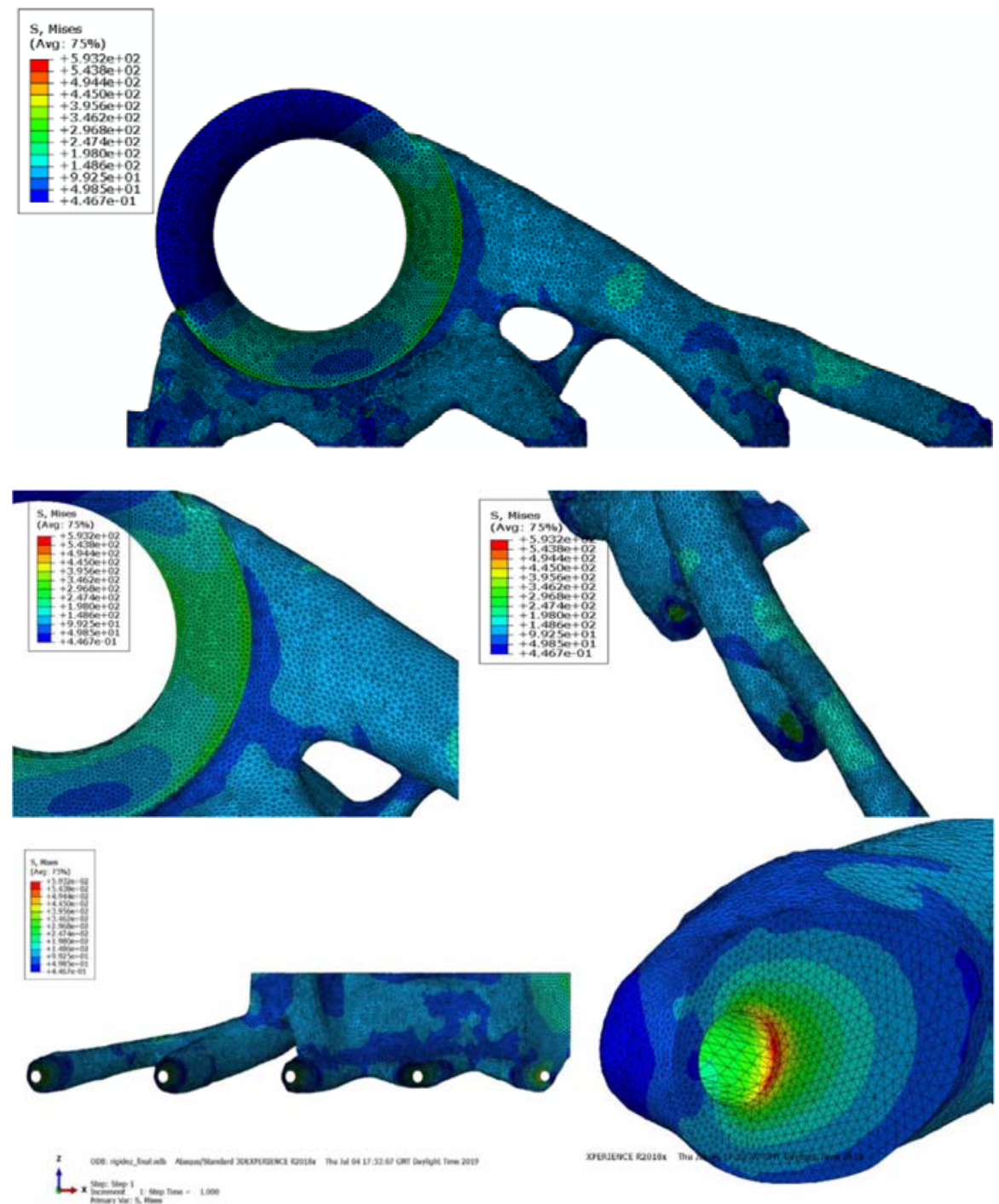

Figure 12: Static analysis of the final optimized component (Von Mises stress field for peak load of 34155 N): global overview and details around spherical bearing and gripping holes.

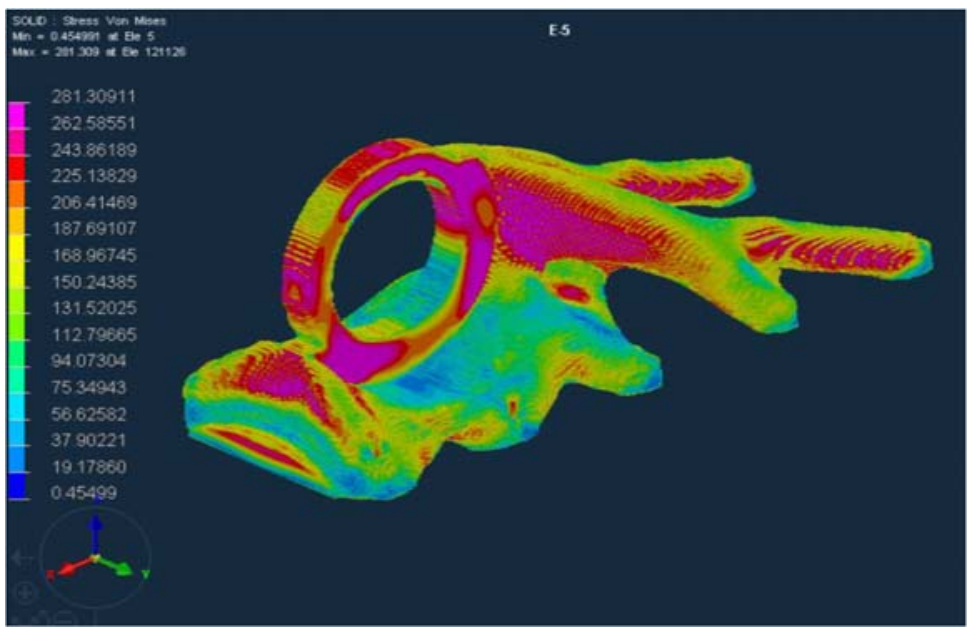

Figure 13: Residual stress distribution for Orientation 1. 


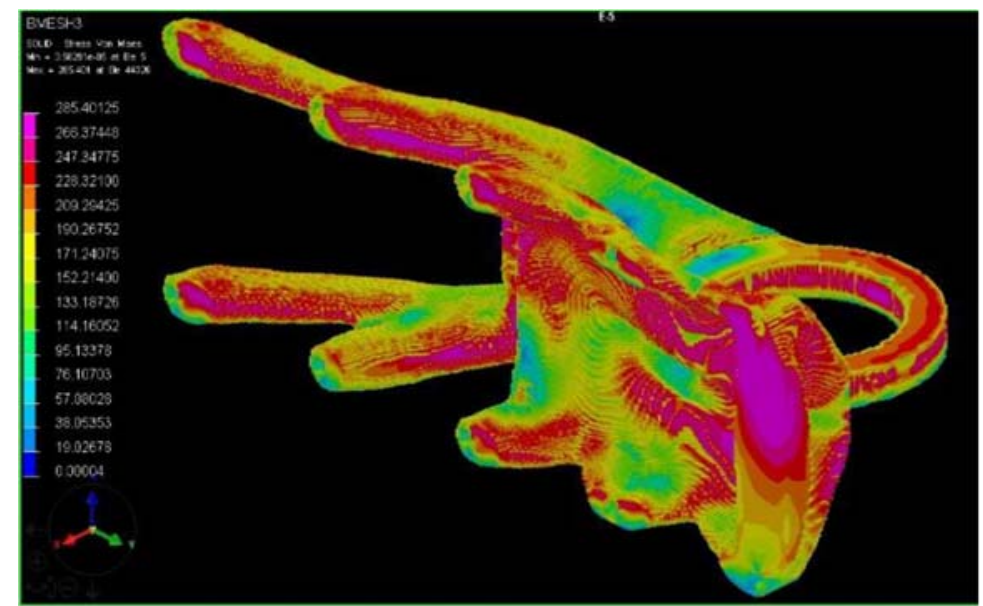

Figure 14: Residual stress distribution for Orientation 2.

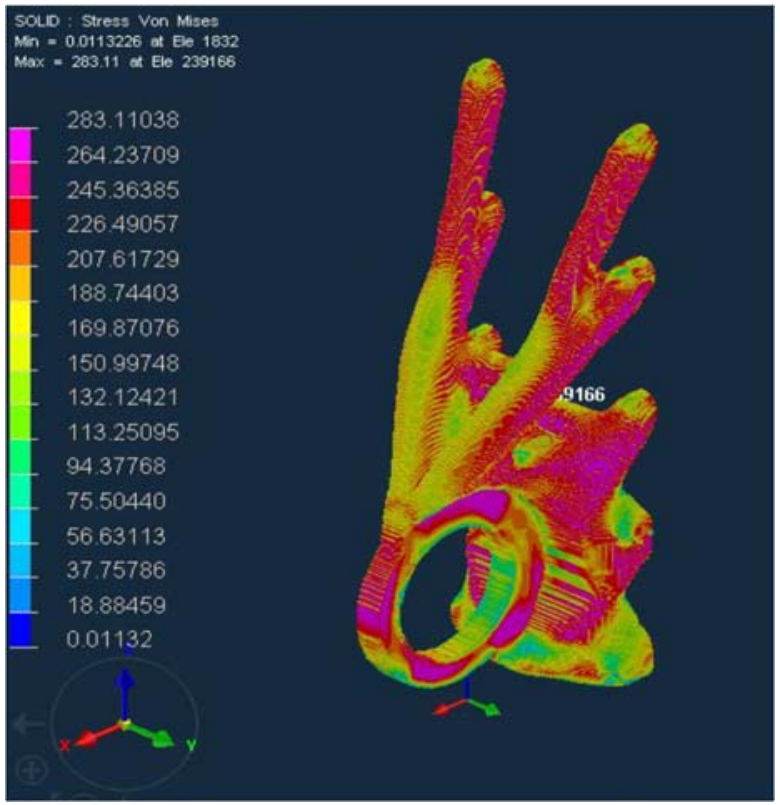

Figure 15: Residual stress distribution for Orientation 3.

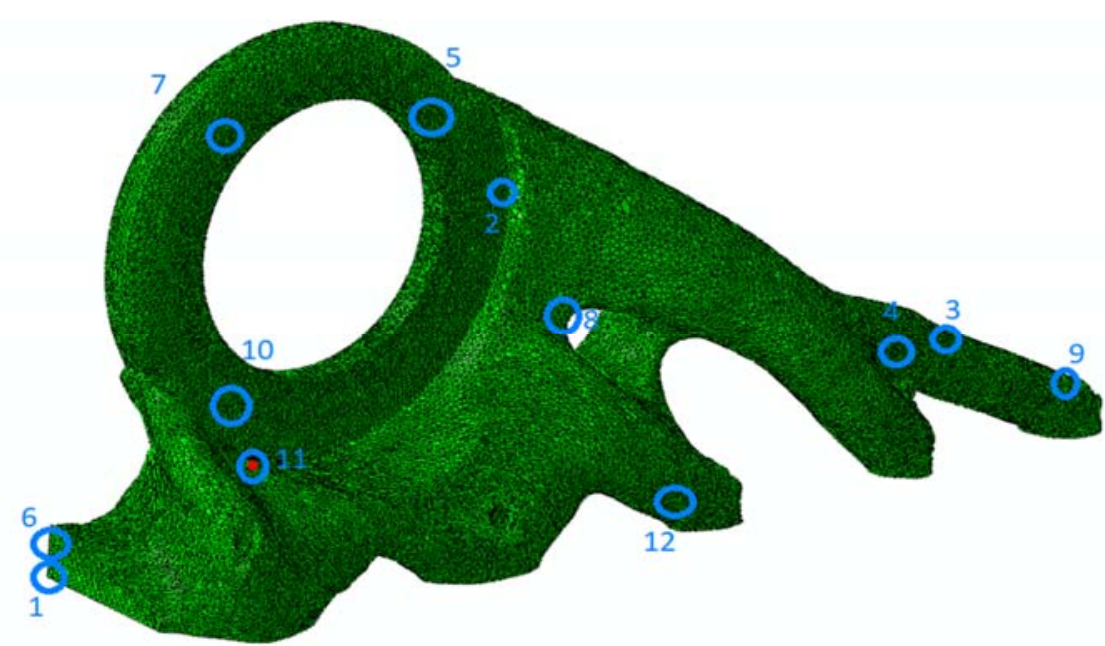

Figure 16: Potential critical points provided by high stress areas resulting from TO and AM simulations. 
Based on the S-N curve presented in Fig. 3, it was possible to insert the equivalent stress computed at each selected potential critical point for an applied load of $34155 \mathrm{~N}(\mathrm{R}=-1)$. Fig. 17 presents the fatigue results for the Orientation 1. The group of points called "No Residual Stress" are the ones where only the cyclic load is present, and since the load ratio on this study is -1 , they result on a null mean stress, therefore are located exactly on the S-N curve. Accounting the effect of the residual stress, it can be noticed that it has a detrimental effect on fatigue behavior for all points. The tensile residual stress obtained from AM simulation process for the purpose locations and taking into account the referred orientation have led to a reduction on the estimated number of cycles. Consequently, it can be stated that for the present orientation the residual stress due to manufacturing process will reduce the fatigue life of the component, from $1.1 \times 10^{5}$ cycles to $2.0 \times 10^{4}$ cycles as can be observed in the Fig. 17.

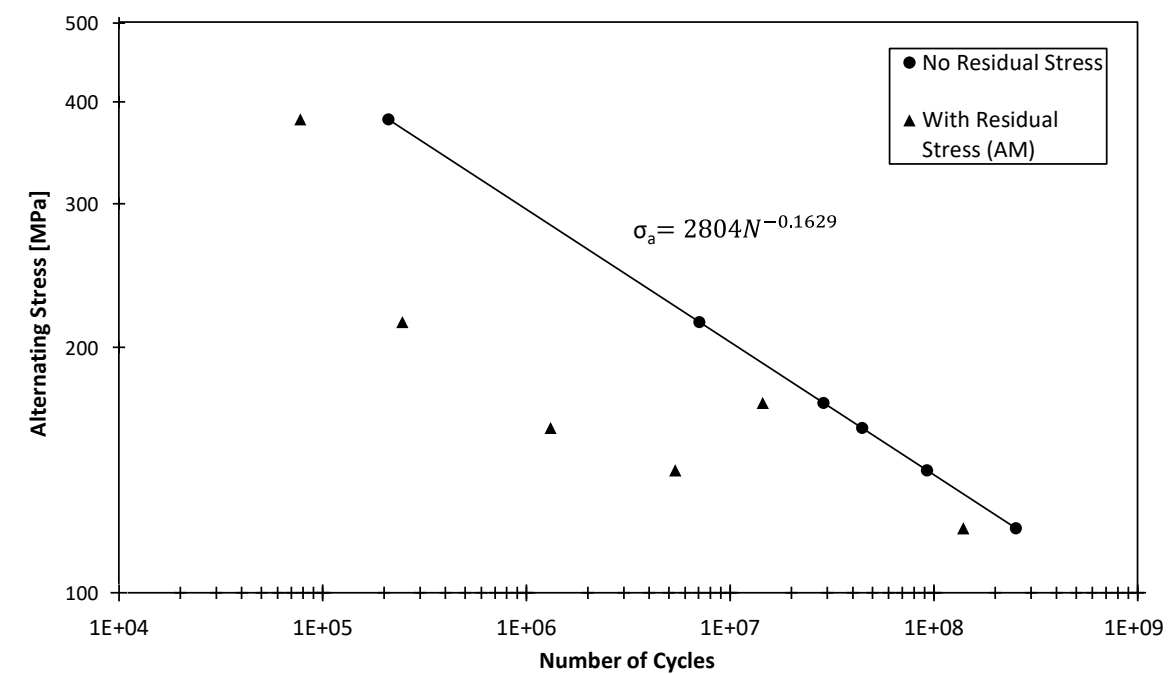

Figure 17: SN curve considering the alternating stress points and the mean stresses for build orientation 1.

For the second studied building orientation, the results are presented in Fig. 18. This manufacturing orientation presented an interesting and promising effect. Ignoring the residual stresses, the most critical point for fatigue was the point 2 (the same as in orientation 1). However, this point presented compressive residual stresses, which are beneficial for fatigue. Hence, taking into account the residual stresses, the fatigue behaviour of this region was improved. Due to the residual stress originated by the AM, the overall fatigue life of the component was improved, increasing from $1.1 \times 10^{5}$ cycles to $5.0 \times 10^{5}$ cycles. In addition, the region of failure was no longer around point 2 , moving to the point 1 .

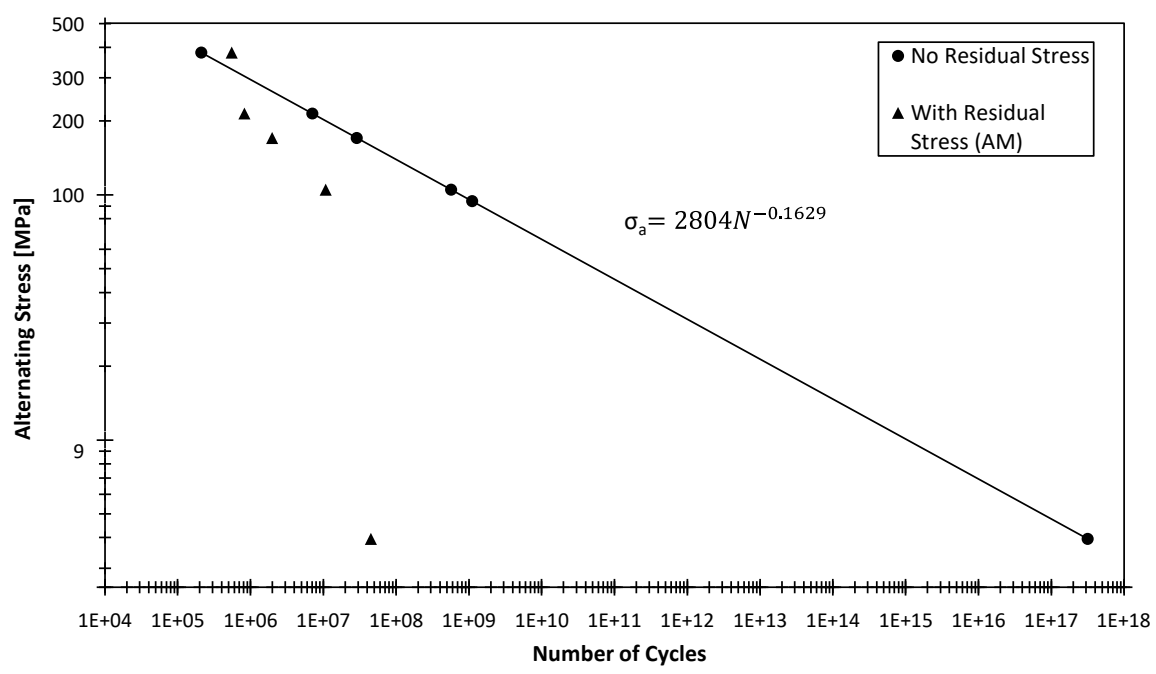

Figure 18: SN curve considering the alternating stress points and the mean stresses for build orientation 2. 
Concerning the third building orientation, Fig. 19 illustrates the fatigue results. The results where similar to the ones on Orientation 1, i.e. the residual stresses are all tractive at selected potential critical points, significantly reducing the strength of the component under cyclic loads. One may figure out that the build orientation may have an impact on fatigue resistance of the component, being the build orientation 2 the most favourable since it induced compressive residual stresses at the most critical point under external loading. Therefore, the AM process parameters may be selected to produce favourable residual stresses. In addition, it is clear that the residual stresses at the surface are generically positive (tensile), therefore post-processing techniques aiming at residual stresses relief would be beneficial towards the global fatigue performance of the part. It is worth mentioning that besides the residual stresses, the build direction also influences the surface roughness, which need to be accounted in fatigue assessment. Nevertheless, this surface geometric feature cannot be conveniently modelled with FEA.

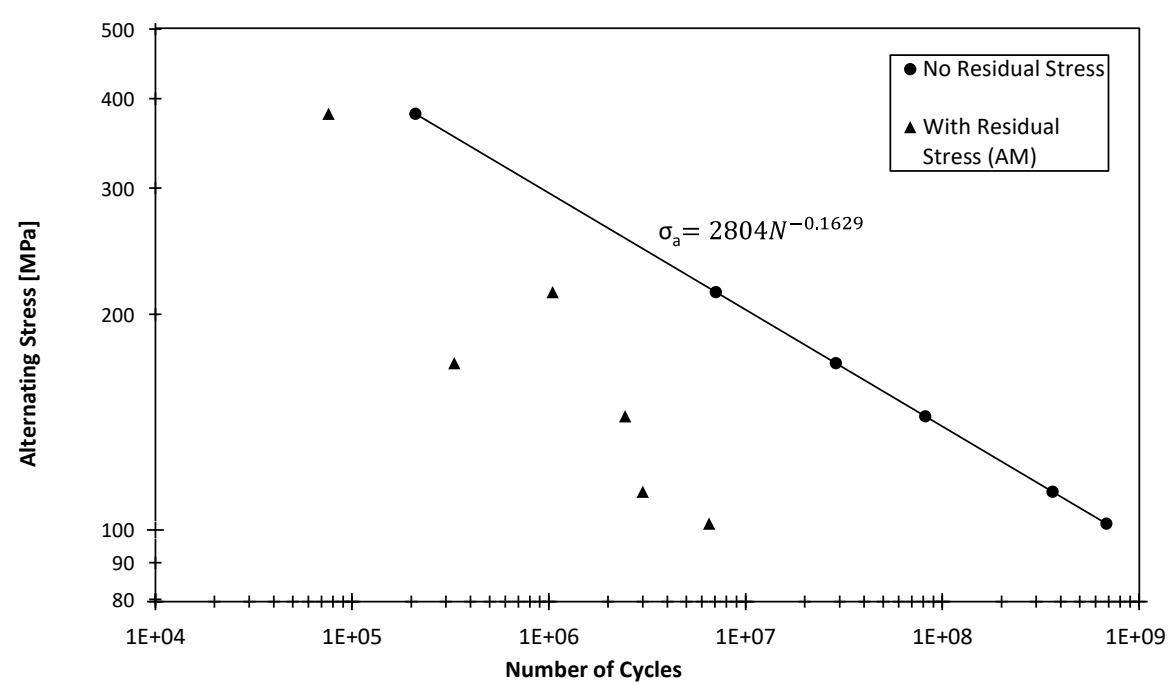

Figure 19: SN curve considering the alternating stress points and the mean stresses for build orientation 3.

\section{CONCLUSIONS}

he optimization methodology proposed was able to find an efficient geometry, fulfilling the design requirements. The present case study was based on a well-known case study picked from literature, which allowed the validation of some stages of the methodology namely the topology optimization stage. The main conclusion for the proposed study are summarized below:

- The optimization methodology applied on the present work was proved to be efficient. The volume (and the mass) of the optimized component was only $12.53 \%$ of the initial domain. The stiffness to mass ratio was almost 6 times higher than the initial value.

- The post-processing approach on the geometry resulted in more homogenous stress field. Sharp edge and abrupt changes in surface were smoothed, resulting in lower stresses concentration on these locations.

- The residual stresses due to the AM process presented a significant effect on fatigue. Therefore, when it must be considered during the design stage of parts subjected to cyclic loads.

- The fatigue performance of a component showed to be strongly dependent on the building orientation. Build orientation 2 presented the highest fatigue life. Compressive residual stresses shift the critical point to an alternative location. Thus, component design may account for construction parameters in order to produce beneficial residual stresses.

- Besides the built direction, other manufacturing parameters such as the scanning strategy, layer thickness and laser power could be handled to produce favourable residual stresses. Nevertheless, this investigation would require accurate process simulation tools allowing a truly digital twin of the process.

Future challenges would be to demonstrate the proposed methodology based on experimental program. Also, residual stresses are one variable affecting the fatigue damage, but surface roughness and internal defects, which also depends on the manufacturing parameters, would influence the fatigue damage as well. 


\section{ACKNOWLEDGMENTS}

he projects Add.Strength entitled "Enhanced Mechanical Properties in Additive Manufactured Components" (Reference PTDC/EME-EME/31307/2017) and "MAMTool - Machinability of Additive Manufactured Parts for Tooling Industry" (Reference PTDC/EME-EME/31895/2017) funded by the Programa Operacional Competitividade e Internacionalização, and Programa Operacional Regional de Lisboa funded by FEDER and National Funds (FCT) are acknowledged.

\section{REFERENCES}

[1] Dilberoglu, U.M., Gharehpapagh, B., Yaman, U., Dolen, M. (2017). The Role of Additive Manufacturing in the Era of Industry 4.0, Procedia Manuf., 11, pp. 545-554, DOI: 10.1016/j.promfg.2017.07.148.

[2] Holmberg, E. (2013). Stress and fatigue constrained topology optimization. Linköping Univeristy, 2013.

[3] Gibson, I., Rosen, D., Stucker, B. (2015). Additive manufacturing technologies: 3D printing, rapid prototyping, and direct digital manufacturing, second edition. Additive Manufacturing Technologies: 3D Printing, Rapid Prototyping, and Direct Digital Manufacturing, Second Edition, New York, Springer, pp. 1-498.

[4] Tripathy, S., Chin, C., London, T., Ankalkhope, U., Oancea, V. (2017). Process Modeling and Validation of Powder Bed Metal Additive Manufacturing. NAFEMS World Congress 2017.

[5] Yap, C.Y., Chua, C.K., Dong, Z.L., Liu, Z.H., Zhang, D.Q., Loh, L.E., Sing, S.L. (2015). Review of selective laser melting: Materials and applications, Appl. Phys. Rev., 2(4), pp. 041101, DOI: 10.1063/1.4935926.

[6] Yang, L., Hsu, K., Baughman, B., Godfrey, D., Medina, F., Menon, M., Wiener, S. (2017). Additive Manufacturing of Metals: The Technology, Materials, Design and Production, Springer.

[7] Bhavar, V., Kattire, P., Patil, V., Khot, S., Gujar, K., Singh, R. (2017). A review on powder bed fusion technology of metal additive manufacturing. Additive Manufacturing Handbook, CRC Press, pp. 251-253.

[8] Kurzynowski, T., Chlebus, E., Kuźnicka, B., Reiner, J. (2012).Parameters in selective laser melting for processing metallic powders. In: Beyer, E., Morris, T., (Eds.), p. 823914.

[9] Zumofen, L., Beck, C., Kirchheim, A., Dennig, H.-J. (2018). Quality Related Effects of the Preheating Temperature on Laser Melted High Carbon Content Steels. Industrializing Additive Manufacturing - Proceedings of Additive Manufacturing in Products and Applications - AMPA2017, Cham, Springer International Publishing, pp. $210-219$.

[10] Nicoletto, G., Konečna, R., Frkan, M., Riva, E. (2020). Influence of layer-wise fabrication and surface orientation on the notch fatigue behavior of as-built additively manufactured Ti6Al4V, Int. J. Fatigue, 134, pp. 105483, DOI: $10.1016 /$ j.ijfatigue.2020.105483.

[11] Nicoletto, G. (2020). An Efficient Test Method for the Quantification of Technology-Dependent Factors Affecting the Fatigue Behavior of Metallic Additive Manufacturing Components. Structural Integrity of Additive Manufactured Parts, 100 Barr Harbor Drive, PO Box C700, West Conshohocken, PA 19428-2959, ASTM International, pp. $484-506$.

[12] Nicoletto, G. (2020). Influence of Rough As-Built Surfaces on Smooth and Notched Fatigue Behavior of L-PBF AlSi10Mg, Addit. Manuf., 34, pp. 101251, DOI: 10.1016/j.addma.2020.101251.

[13] Nicoletto, G. (2019). Smooth and notch fatigue behavior of selectively laser melted Inconel 718 with as-built surfaces, Int. J. Fatigue, 128, pp. 105211, DOI: 10.1016/j.ijfatigue.2019.105211.

[14] Kranz, J. (2017). Methodik und Richtlinien für die Konstruktion von laseradditiv gefertigten Leichtbaustrukturen, .

[15] Sander, P. (2016). On the way to Additive Manufacturing Chances \& Challenges for the Future Design , Industrial Production Emerging Technologies \& Concepts. World PM2016 congress and exhibition, Hamburg.

[16] Zhong, Y., Rännar, L.E., Liu, L., Koptyug, A., Wikman, S., Olsen, J., Cui, D., Shen, Z. (2017). Additive manufacturing of 316L stainless steel by electron beam melting for nuclear fusion applications, J. Nucl. Mater., 486, pp. 234-245, DOI: 10.1016/j.jnucmat.2016.12.042.

[17] Angelova, D., Yordanova, R., Lazarova, T. (2014). On factors influencing fatigue process in steel 316L used in hydrogen energy technologies, J. Chem. Technol. Metall., 49(1), pp. 29-34.

[18] Roy, S.C., Goyal, S., Sandhya, R., Ray, S.K. (2012). Low cycle fatigue life prediction of 316 L(N) stainless steel based on cyclic elasto-plastic response, Nucl. Eng. Des., 253, pp. 219-25, DOI: 10.1016/j.nucengdes.2012.08.024.

[19] Nikolas Taillieu. (2016). A topology optimization framework for additively manufactured materials under mechanical load. 2016.

[20] Bendsøe, M.P., Sigmund, O. (2004). Topology Optimization, Berlin, Heidelberg, Springer Berlin Heidelberg. 
[21] Liu, J., Ma, Y. (2016). A survey of manufacturing oriented topology optimization methods, Adv. Eng. Softw., 100, pp. 161-175, DOI: 10.1016/j.advengsoft.2016.07.017.

[22] Cazacu, R., \& Grama, L. (2014). Overview of structural topology optimization methods for plane and solid structures, Ann. Univ. Oradea, Fascicle Manag. Technol. Eng., 23(3), pp. 1583-1591.

[23] Johnsen, S. (2013). Structural Topology Optimization: Basic Theory, Methods and Applications.

[24] ANSYS. (2017). Topology Optimization R18.0 Feature and Usage Highlights: Additive Manufacturing Application.

[25] Desmaison, O., P-A. Pires, Levesque, G., Peralta, A., Sundarraj, S., Makinde, A., Jagdale, V. and Megahed, M. (2017). Influence of computational grid and deposit volume on residual stress and distortion prediction accuracy for additive manufacturing modeling. In Proceedings of the 4th World Congress on Integrated Computational Materials Engineering (ICME 2017), pp. 365-374. Springer, Cham.

[26] Stephens, R.I. (Ralph I., Fuchs, H.O. (Henry O. (2001). Metal fatigue in engineering.

[27] Gough, H.J., Sines, G. (1959). Behavior of metals under complex static and alternating stresses, Sines G, Waisman JL, Ed. Met. Fatigue. Met. Fatigue, 1, pp. 145-69. 